\title{
Preparation of University Students to Be Role Models in General Biology Laboratory
}

\author{
A. Almuhammadi ${ }^{1}$, A. Khallaf ${ }^{1}$, D. Abuljadayel ${ }^{1}$, D. Alsudairi ${ }^{1}$, H. Ashqar ${ }^{1}$, H. Alharbi ${ }^{1}$, I. Alhazmi ${ }^{1}$, N. Zelai ${ }^{1}$, \\ N. Hakami ${ }^{1} \&$ R. Alhindi ${ }^{1}$ \\ ${ }^{1}$ Department of Biological sciences, Faculty of Science, King Abdulaziz University, Jeddah, Saudi Arabia \\ Correspondence: N. Zelai, Department of Biological sciences, Faculty of Science, King Abdulaziz University, \\ Jeddah, Saudi Arabia. E-mail: nzelai@kau.edu.sa
}

Received: August 16, 2018

Accepted: September 18, 2018

Online Published: December 28, 2018

doi:10.5539/ies.v12n1p146

URL: https://doi.org/10.5539/ies.v12n1p146

\begin{abstract}
Teaching has become a challenge mission among generations as direct instructions are not effective anymore and; therefore, students need to be convinced for sharing and fulfilling their responsibilities. In this study, students are perceived to act as role models in managing the laboratory classes of general biology. Four groups were classified as co-lecturers, co-technicians, safety group, and green team. This experiment was evaluated by both students and staff team. The results showed that the most effective group was the co-lecturer as it showed high level of cooperation, work with love, truth, motivate others, and team management. The advantages of this experiment were more likeable as compared to the disadvantages; although, participants suggest that more information is needed to improve the group work.
\end{abstract}

Keywords: university students, role models, general biology laboratory

\section{Introduction}

Students need to perform experiments themselves in laboratories to develop their knowledge, while studying Biology. Therefore, laboratories are considered as obligated component in biology courses (NABT, 2005). Many countries develop their laboratory curriculums and teaching methods to keep pace with current progression in education. Malaysian Government admits a policy in science and technology to cope with developments in the education sector (Mahathir, 1991). In addition, among 22 teaching methods, one of the positive features of teaching methods that have been used in Finland is students group working and participating in the teaching processes. Another aspect is the development of psychomotor skills such as laboratory tools, as laboratory is the environment in which students can gain experimental skills and learn how studies are conducted (Jeronen et al., 2017). In United States of America, inquiry-based learning is applied in field experience, investigations, and laboratories to obtain accurate real data (Bybee, 2002). Therefore, development of laboratories is an important factor in improving biology teaching strategies in the developing countries.

The working environment in traditional laboratories was either working individually or in pairs. However, institutions are under immense pressure for considering increase in capacity of laboratory classes and experiences, associated with the benefits involving students (Ott et al., 2018). There is lack of evidence about how students perceive team roles and promote team interdependence in a learning environment, despite of increased usage of team roles within a cooperative environment. Specific roles are needed to be assigned to the students for developing positive interdependence and provide students with increased exposure to various roles enacting by the scientists (Ott et al., 2018). Role models in education are ethical leaders who are symbols of special achievement and offer outstanding services (Allen, 2000).

Female role models can clearly affect the attitude of young women even in limited-time meeting (Porter and Serra, 2017). A study has shown that adult role models having the same race, gender, and age could improve student academic performance (Kaziboni and Uys, 2015). Thus, role models have a great influence on student's ability to learn. As role models have great effects on their community, it is much effective to prepare students themselves to be role models. In Makah, Saudi Arabia, "How to be a role model" is an intellectual cultural project that is applied in all governmental and private spheres. In King Abdul-Aziz University, laboratories have same credit hours as basic lectures as it is believed that students need to experience what they learn. As per the knowledge, this study is the first in the field of preparation of students to be role models in the context of Jeddah, Saudi Arabia. Therefore, 
the study aims to apply the concept of role model in general biology laboratories by admitting group working leaders. Electronic survey has been used within different groups to observe and evaluate collaboration and integration among them.

\section{Literature Review}

A very few studies have been carried out about the significance of teaching methodology in biology and environmental education, which also includes outdoor education for sustaining the primary, secondary and pre-service teacher education level (Makransky, 2016; Jayasuriya-Illesinghe, 2016; Haider, 2016; Jeronen, 2016). For instance, Jeronen (2016) evaluates the keywords related to biology and sustainable in terms of various scientific databases. However, 24 articles based on peer-reviewed scientific journals from 2006 to 2016 were reviewed to conduct the studies. The study mainly focused on teaching methodology, knowledge and thinking capabilities, emotions and attitude, psychomotor skills, learning environment and the evaluation method. The study found teaching method to be most effective and stated that students should be actively participated in the learning procedures. The study concluded that teaching methods are seemed to be valuable here that offer beneficial supportive instructions and supports active involvement.

Makransky (2016) examined the virtual laboratory simulation (vLAB) that can be utilized to change face to face perception to train students for the laboratory practices in the microbiology laboratory. For conducting this study, 189 students were randomly selected, who were engaged in the undergraduate biology course for the (vLAB) test and demonstration. Additionally, all the participants were evaluated on the basis of their ability to perform the laboratory-based techniques. They were also assessed through the pre and post-test to identify their level of knowledge of microbiology, innate encouragement to study extensively about microbiology, and their efficiency level in the field of microbiology related to the experiments. The study found no significant difference between the groups as both the groups were identified with the similar level of increased knowledge of microbiology, self-efficiency, and motivation to study microbiology. However, the study suggested that the (vLAB) can be utilized instead of the direct face to face tutorials. (vLAB) for the future science education.

Jayasuriya-Illesinghe (2016) studied the experiences of undergraduate medical students during their clinical training in their final year to investigate the teaching-learning experiences. Interviews were conducted in which twenty-eight graduate students from three different medical schools were interviewed individually. The interview recordings were transcribed using qualitative analysis method. The study revealed 2 types of teaching and learning experiences, objectified teaching and role modelling. Role modelling is about observing the teachers during the time they conduct their experiments. However, role modelling got failed to have a positive impact on the learning experiences. In contrast, the purposeful teaching let the students and teachers to interact to the effective interaction between students and teacher through which a true experience of role mode can be observed. Student's interest and their responses were based on the teacher's behaviours, their teaching methodology, and attitudes. The study concluded that the difference between role modelling and purposeful teaching should be highlighted in the student's clinical training situations. The extensive knowledge of the clinicians and their attitudes, behaviours, and characteristics lead towards better teaching-learning experience.

The role model methodology allows students to learn and help them in the professional identity development. However, the choice of role model depends on the cultural values and social organization. Considering the difference between South East Asia and the other countries regarding the social organization and cultural values, Haider (2016) identified its importance whether it has an influence on the characteristics of medical students looking for their role models in the society. Questionnaire based on 32 items were designed and given to the undergraduate medical students. The groups of the participants were compared by using student's t-test and ANOVA. The study concluded that there are some attributes, which can be perceived as beneficial for role models. Additionally, these advantageous attributed for the desired role model that can assist the medical educators to define some strategies, which strengthen the attributes in their institutions.

Tenenbaum (2014) aimed to study the mentoring model and near-peer mentorship that lead to the development of mentor and mentee, initiated developed principles of mentoring, and provided different opportunities to combine research and teaching in the internship of science, technology, engineering and mathematics (STEM). The results revealed that mentorship model contributes to the professional, personal and education growth, and enhance the interest level and involvement of the students studying (STEM).

\section{Method}

\subsection{Description of the Study Groups}

This study has been conducted in King Abdul-Aziz University, Jeddah, Saudi Arabia. The study was supervised by 
six lecturers, two technicians, and two assistant professors. The study was performed in the two semesters of the academic year 2017/2018. First semester contained control group (480 students in 16 labs), who did not take the responsibility as a role model. These students only took instructions from the lecturers and technician on applying safety rules, cleaning of their labs, helping others by explaining difficult experiments, and helping technicians in preparation of labs.

In the second semester, a total of 238 students were divided in 10 labs, who were treated as role models in general biology labs. First group decided to be role models in applying the safety rules and teach others. Second group decided to be role models as a green team that would maintain the lab environment clean and neat. Third group students chose to be role models as co-lecturers helping the lecturers in teaching and explain any difficult experiment to other students. The last group students worked as co-technician to assist the lab technician in preparation of the new labs.

\subsection{Data Collection}

A quantitative research methodology in the form of a self-administered survey was employed to test whether the sharing of responsibilities in group working by application of role models' concept was effective or not. The survey was given to all students and staff members to check their opinion in this experiment.

\subsection{Data Analysis}

The collected data was reviewed and analysed to find the conclusion. All charts were drawn by using Graphpad prism software.

\section{Results}

A total of 104 responses were randomly collected from students and staff members, who participated in this study (Figure 1). The survey questions were responded by $41.6 \%$ of the total students ( 99 of 283 ), $80 \%$ of lecturers, and $50 \%$ of technicians.

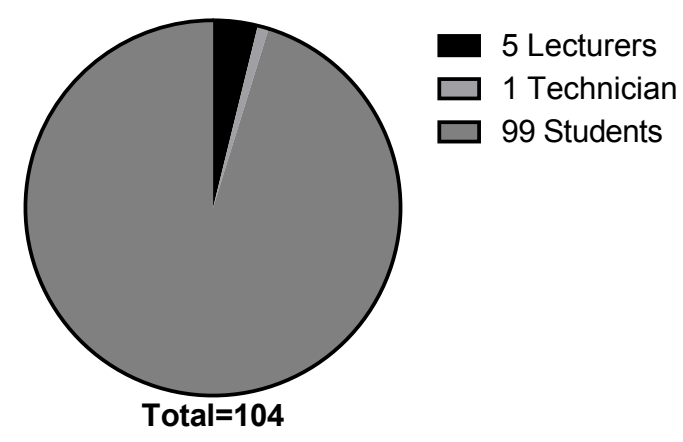

Figure 1. Number of students and staff members who participated in filling the survey

The participants of this survey were given more than one option to choose from the ethics and values that they believe were applied by students of general biology as compared with the control group (Figure 2). Majority of the students and staff members thought that co-lecturers showed better ethics and values among other groups. The evaluation showed that $50 \%$ of the participants believed that co-lecturers have the concept of truth, $82 \%$ agree that they cooperate with others, $69.2 \%$ think that they work with love, $18.3 \%$ observe that they add a creative touch, and $32 \%$ and $48 \%$ consider that this group was characterized with team management and motivation of the others, respectively (Figure 2). These values are the most important aspects of the true lecturers. As lecturers are the centres of biology classes, they need to regularly contact the assistant professors to take their instructions, cooperate with the technicians in the lab, contact other lecturers to make standardized tests, and sit with each student in the lab to teach them the lab skills. Therefore, co-lecturer students achieved the most important feature of the role model lecture.

On the other hand, $48.1 \%$ of the participants evaluated co-technicians as the most efficient group among others. Real technicians face many difficulties in their job. They sterilize the lab, prepare samples and solutions, weight chemicals, adjust microscope slides, and anaesthetize the experimental animals before the lab starts. All these duties taught the concept of patience to the co-technician role models that was absent in the control group (Figure 3). Dedication and time management were the most important values that were clearly observed in laboratory 
safety groups compared with control group. Applying of safety rules need leaders who can manage their time and check all the rules before the lab starts. It also needs dedicated models who take care of student's protection in the lab. Accordingly, role models of safety group acquired the most beneficial characteristics from their work as compared with control group.

As the green team start their work after the lab time, the responsible role models of this group started their job with cleaning and arranging their places without any instructions or monitoring from others, compared with the control group who only took instructions from the lecturer, as compared with the control group who only took instructions from the lecturer.

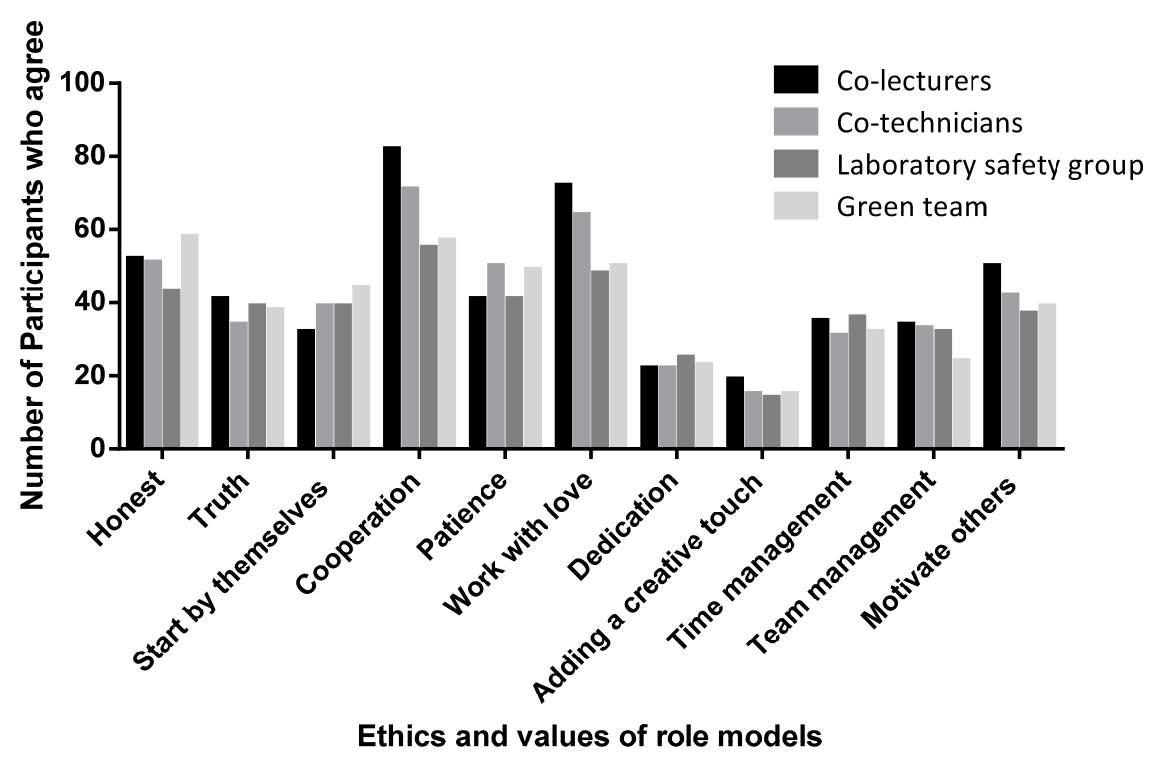

Figure 2. The positive characteristics of the role model groups compared with the control

Both positive and negative sides must be taken in the consideration to apply any new experiments. A percentage of $33.9 \%$ of the participants observed that co-lecturer did not start their own work, but help others first. In addition, $44.9 \%$ of the work team thought that co-lecturers need more information about their role to do it in better way. On the other hand, $15.3 \%$ of the survey filler observed that the safety group members were arrogant. Some participants $(17.2 \%)$ considered the green team as non-cooperative group as they did all the work themselves rather that sharing others. Students needed more clarification about the leadership, kindness, sharing responsibilities with other groups, and explanations of their duties, as this was the first experiment for the students as being role models. 


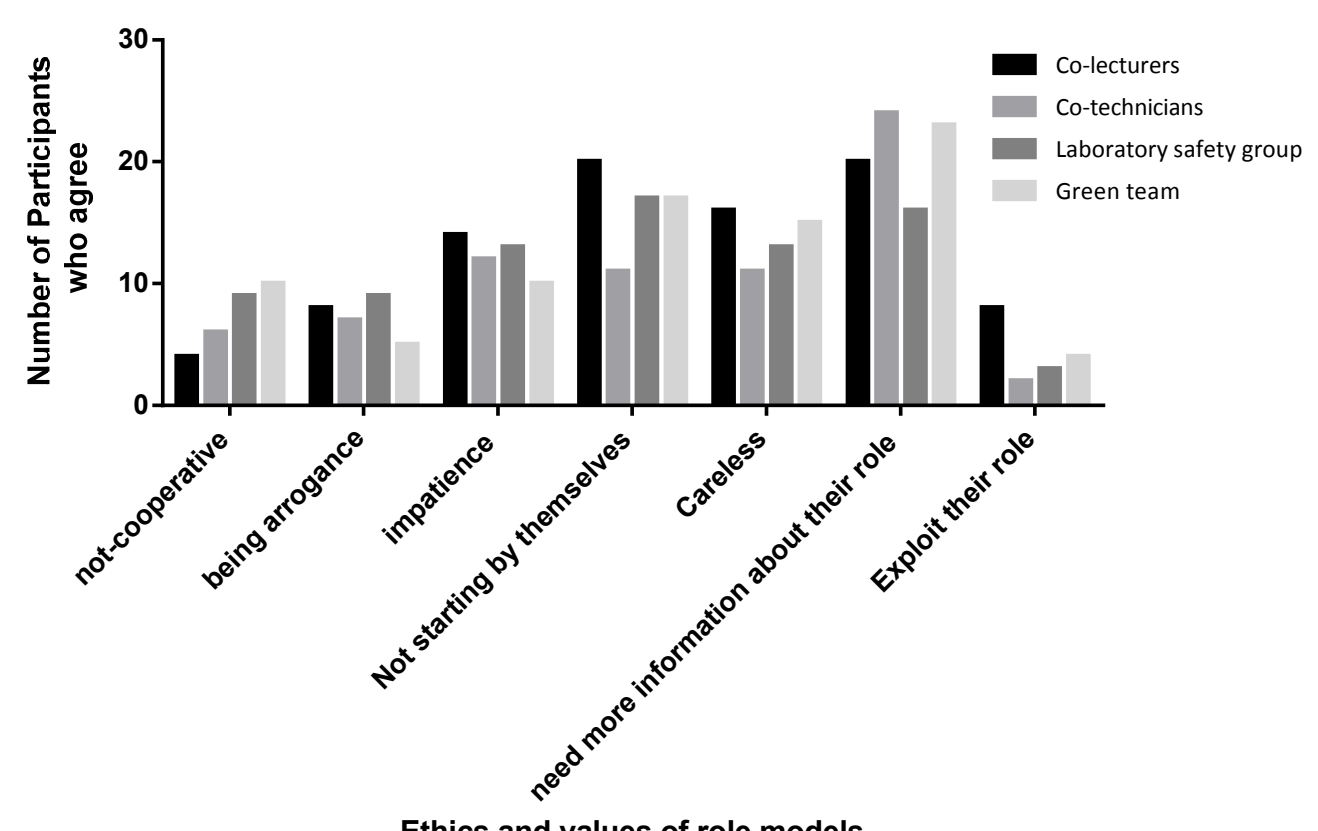

Figure 3. The positive characteristics of the role model groups compared with the control

In general, the percentage of the acquired positive characteristics was much more than the negative (Figure 4). The most abundant positive feature was cooperation among group members; while, the most voted negative point was that student need more information about their work.

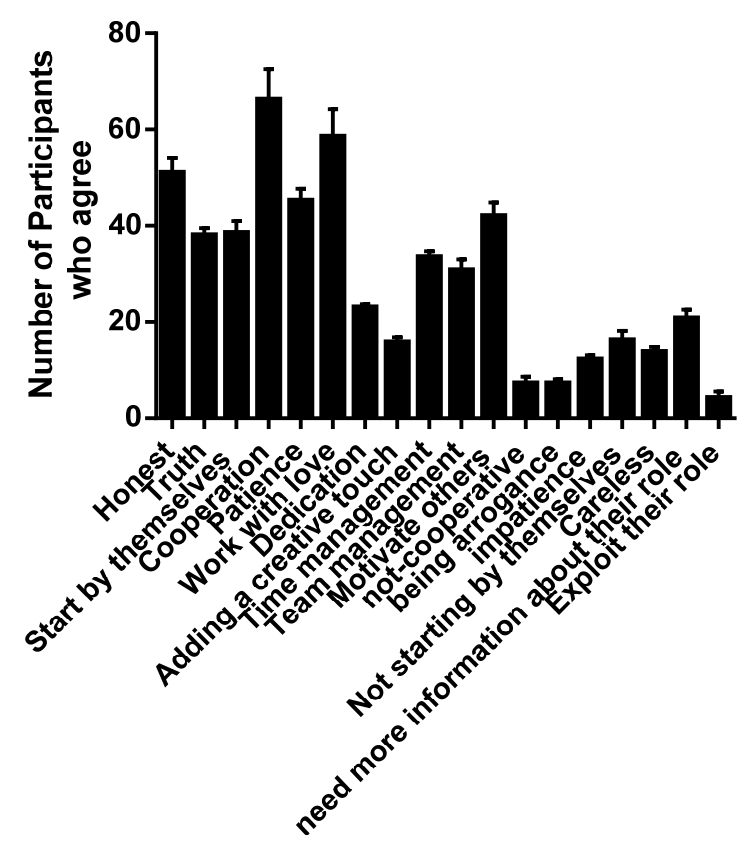

Positive and negative characteristics of role model groups

Figure 4. Differentiation between the positive and the negative aspects of role models

Finally, some statements were included in the survey to be evaluated by the participants. The majority of the participants evaluate the statements as excellent according to what they experience in this study (Figure 5). 


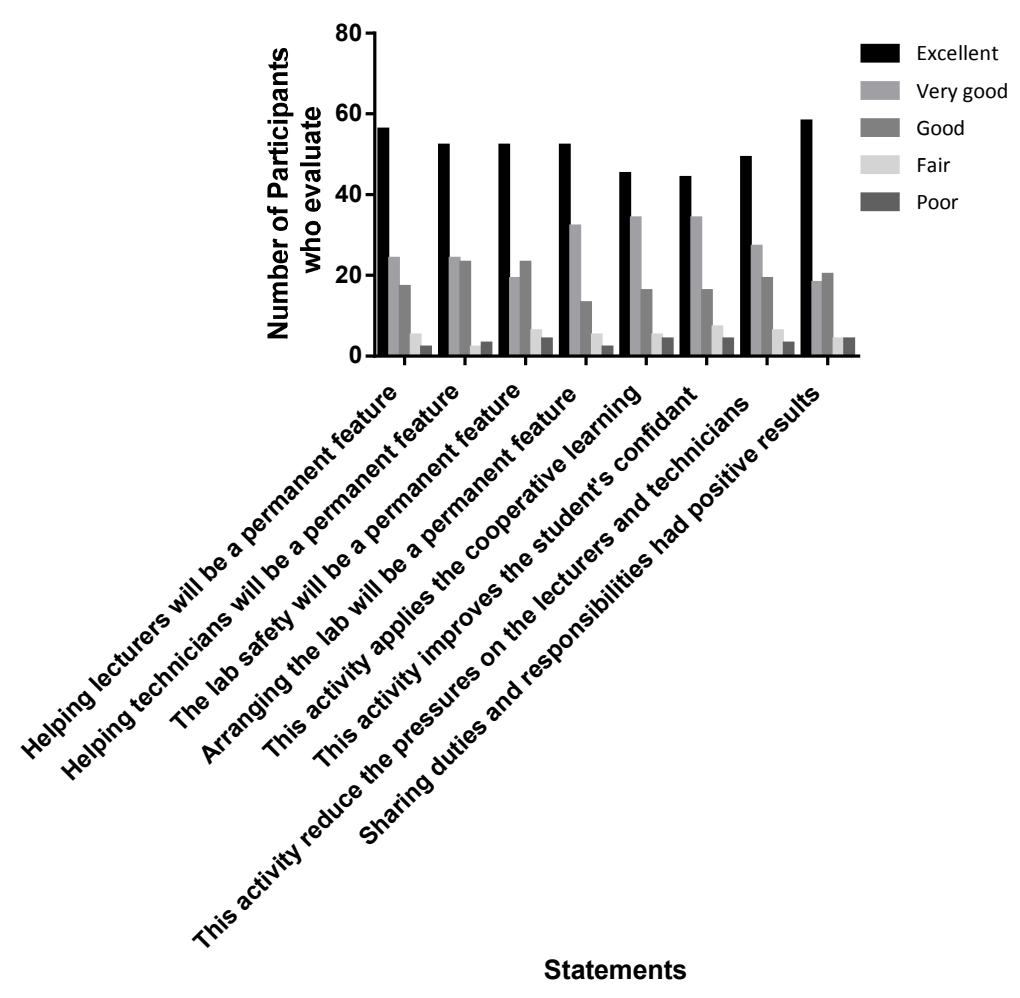

Figure 5. General evaluation of the study

\section{Discussion}

The study aimed to identify the preparation of University students to be role models in General Biology laboratory. Moreover, in the clinical area, recent passed out students and current students were evaluated in terms of role modelling. The exposition of the students towards both negative and positive role models and its effect on the clinical and academic situations was analysed by Jack, Hamshire, and Chambers (2017) using the existing literature on nursing and medical. Thus, the excitement referring to teaching and its positive approach towards the students has been recognized as a significant aspect for the effective learning. However, these models can affect the student's behaviours positively in the learning environment. Furthermore, Morgenroth, Ryan, and Peters (2015) offered an integrated framework, which is used to identify the ways in which role models encourage their role model aspirants. It has many contributions in the role model literature as well. Moreover, this theoretical framework assists in bringing all the literatures based on role model together and give and extensive meaning to the impact of the single paper. Furthermore, the theoretical framework also stepped forward towards the understanding of the procedures through which the role aspirants may get motivated and their aims and objectives got influenced. However, the perception of role model cannot be understood until role aspirants get examined themselves and the encouragement processes appears among them.

According to Bijari et al. (2016), there was a strong relationship between humanistic attributes of the teacher's demonstration and the perception of role models among the students. The study has recommended that academic institutions should take steps to develop and enhance the role modelling of the teachers and faculty members by emphasizing on the humanistic attributes of the role model in teachers whether clinical or academic. In contrary, as medical education is about being a doctor and by being a doctor, an individual need to take care of the patients under the controlled situations of the care and safety. However, teachers are always aware of the learner's opinion and be ready to face various requirements about the humanistic and professional results of their teaching methods. Moreover, institutions should provide guidance to the development of the faculty and its activities to present students with the extensive range of role models like teacher, researcher, and specialist. These are according to the diverse expectations, discipline and their needs. Whereas, Palaniandy (n.d) showed a positive association between the lecturer frankness, lecturer attributes, professionalism and students taking care of the lecturer. Moreover, a significant link was also found between lecturer's negative attributes and student's negative perceptions. However, when it comes to gender, no significant change was observed between male and female students in terms of all 
dimensions considered.

There was a significant association between lecturer's friendliness and the aspects that were recognized by the students negatively. In terms of lecturer's friendliness, the local students were identified to agree as compared to the foreign counterparts. Whereas, the foreign students seem to agree more on the negative aspects of the lecturer as compared to the local students. Furthermore, the undergraduate students agreed more on the lecturer's friendly quality as compared to the post graduates. However, only the concept of friendliness has been differed as the undergraduate students agree more on the lecturer's friendliness, as compared to the postgraduate students. In terms of age groups, a prominent change has been identified in the lecturer friendliness. This indicated that the younger students agree more on the lecturer friendliness; however, the undergraduates here are generally the youngest population (Palaniandy, n. d). The study has concluded that preparation of students to be role models is a successful method in improving both their work performance and their personal attribute. It is recommended to apply this concept on larger groups and more duties in future studies.

\section{Acknowledgements}

The author is very thankful to all the associated personnel in any reference that contributed in/for the purpose of this research. Further, this research holds no conflict of interest and is not funded through any source.

\section{References}

Allen, A. L. (2000). The role model argument and faculty diversity. National Academy of Engineering, Online Ethics Center.

Bijari, B. B., Zare, M., Haghdoost, A. A., Bazrafshan, A., Beigzadeh, A., \& Esmaili, M. (2016). Factors associated with students' perceptions of role modelling. International journal of medical education, 7, 333. https://doi.org/10.5116/ijme.57eb.cca2

Bybee, R. W. (2002). Biology education in the United States: The unfinished century. AIBS Bulletin, 52(7), 560-567. https://doi.org/10.1641/0006-3568(2002)052[0560:BEITUS]2.0.CO;2

Haider, S. I., Snead, D. R., \& Bari, M. F. (2016). Medical students' perceptions of clinical teachers as role model. PloS one, 11(3), e0150478. https://doi.org/10.1371/journal.pone.0150478

Jack, K., Hamshire, C., \& Chambers, A. (2017). The influence of role models in undergraduate nurse education. Journal of clinical nursing, 26(23-24), 4707-4715. https://doi.org/10.1111/jocn.13822

Jayasuriya-Illesinghe, V., Nazeer, I., Athauda, L., \& Perera, J. (2016). Role Models and Teachers: medical students perception of teaching-learning methods in clinical settings, a qualitative study from Sri Lanka. BMC medical education, 16(1), 52. https://doi.org/10.1186/s12909-016-0576-6

Jeronen, E., Palmberg, I., \& Yli-Panula, E. (2016). Teaching methods in biology education and sustainability education including outdoor education for promoting sustainability-A literature review. Education Sciences, 7(1), 1. https://doi.org/10.3390/educsci7010001

Kaziboni, A., \& Uys, T. (2015). The selection of academic role models by first year University students. Journal of Sociology and Social Anthropology, 6(1), 77-86. https://doi.org/10.1080/09766634.2015.11885648

Mahathir, M. (1991). The way forward. Paper presented to the Malaysian Business Council.

Makransky, G., Thisgaard, M. W., \& Gadegaard, H. (2016). Virtual simulations as preparation for lab exercises: Assessing learning of key laboratory skills in microbiology and improvement of essential non-cognitive skills. PloS one, 11(6), e0155895. https://doi.org/10.1371/journal.pone.0155895

Morgenroth, T., Ryan, M. K., \& Peters, K. (2015). The motivational theory of role modeling: How role models influence role aspirants' goals. Review of General Psychology, 19(4), 465. https://doi.org/10.1037/gpr0000059

NABT. (2005). National Association of Biology Teachers.

Ott, L. E., Kephart, K., Stolle-McAllister, K., \& LaCourse, W. R. (2018). Students' Understanding and Perceptions of Assigned Team Roles in a Classroom Laboratory Environment. Journal of college science teaching, 47(4), 83. https://doi.org/10.2505/4/jcst18_047_04_83

Palaniandy, S. (nd). Student Interpersonal Relationships with Lecturers: A Study of Student Perceived Characteristics of Lecturers' Professional Competencies in Malaysian Tertiary Institutions and Implications for Student Services. Retrieved from http://www.apssa.info/ace_upload_files/apssa_doc1419934158.pdf

Porter, C., \& Serra, D. (2017). Gender differences in the choice of major: The importance of female role models. 
December, Southern Methodist University, Department of Economics Departmental Working Papers, 1705.

Tenenbaum, L. S., Anderson, M. K., Jett, M., \& Yourick, D. L. (2014). An innovative near-peer mentoring model for undergraduate and secondary students: STEM focus. Innovative Higher Education, 39(5), 375-385. https://doi.org/10.1007/s10755-014-9286-3

\section{Copyrights}

Copyright for this article is retained by the author(s), with first publication rights granted to the journal.

This is an open-access article distributed under the terms and conditions of the Creative Commons Attribution license (http://creativecommons.org/licenses/by/4.0/). 